Cadernos de Semiótica Aplicada

Vol. 4.n.2, dezembro de 2006

\title{
A Noção de "Profundidade" na Semiótica
}

\section{On the Notion of 'Depth' in Semiotics}

Ivã Carlos Lopes USP - Universidade de São Paulo

"À memória do mestre e amigo Albert Audubert"

Resumo: O artigo aborda a questão da "profundidade" na semiótica da Escola de Paris, destacando alguns aspectos de uma concepção "vertical" em contraste com uma concepção "sagital" do mesmo problema.

Palavras-chave: epistemologia; profundidade; sentido; Escola Semiótica de Paris

Abstract: This paper focuses on some aspects of the notion of 'depth' in the framework of Paris School Semiotics. Particular attention is given to the opposition between a 'vertical' and a 'sagittal' concept of depth from this specific perspective.

Keywords: epistemology; depth; meaning; Paris School Semiotics

A profundidade tem de se esconder. Pois onde? Na superficie.

Hofmannsthal

Quando nos propomos a questão ingênua de saber o que é que caracteriza a profundidade no mundo do sentido, que é o mundo pelo qual se interessa a semiótica, temos de registrar, antes de mais nada, algumas assimetrias entre a profundidade e a sua contraparte 
inescapável, a superfície. Pensaremos na profundidade como (tonicamente) a extremidade inferior, ou (atonamente) a porção inferior de um eixo espacial verticalmente orientado, por exemplo. Nesse caso, a profundidade liga-se ao domínio do grave e do duradouro (no limite, do interminável), em contraposição à superfície, palco da efervescência e da evolução rápida dos múltiplos elementos figurativos, do frêmito contínuo das formas mais palpáveis do discurso. $\mathrm{Na}$ maioria das teorias da linguagem contemporâneas, essa disposição das problemáticas em níveis verticais é um dos raros laivos de concórdia, demarcando-se contra a tela de fundo das inumeráveis dissensões.

Ir além das aparências, transpondo as superfícies em busca das profundezas, é, ao mesmo tempo, uma das tarefas que propôs desde sempre a filosofia e a construção do saber em geral, incluindo o científico. Tournier (1996, p. 158-60) lembra que, no Ocidente, a questão está colocada pelo menos desde a República, de Platão, com seu mito da caverna. Desde então, é preciso ultrapassar a superfície para procurar as realidades profundas que lhe são subjacentes, e aqui o léxico é bem sintomático. Na tradição principal da filosofia e da ciência ocidentais, as profundezas abrigam tais "realidades" apenas passíveis de reconstrução pela inteligência, o que lhes empresta uma dignidade incomensurável perante as estruturas fenomênicas, aparentes e sensíveis, do mundo superficial. O sensível na superfície, o inteligível na profundidade: durante séculos a fio essa distribuição espacializada se faz sentir nos mais diversos âmbitos discursivos. A virada do século XIX para o XX será marcada por movimentos de insurreição frente a esses hábitos de pensamento: mencionemos, entre outros, a filosofia de Henri Bergson e a fenomenologia de Husserl, esforçando-se por preservar os "dados imediatos da consciência" e os fenômenos sensíveis com os mesmos direitos de cidadania tradicionalmente reservados com exclusividade ao inteligível. Mas os velhos hábitos são tenazes, e aquelas associações muitas vezes seculares continuam a dominar o mundo do senso comum, conforme observamos corriqueiramente nas conversações do dia-adia.

\section{Concepções da "profundidade" em semiótica}

Tem-se estendido, por diferentes vias, o alcance da problemática da "profundidade" em semiótica, conforme teremos oportunidade de discutir adiante. Queremos evocar, inicialmente, um ponto de vista sobre a questão que, embora oriundo de um território vizinho, tem inspirado alguns dos desenvolvimentos promissores ao ser acolhido por essa teoria da linguagem. Num ensaio em que discorre sobre a "profundidade" na ordem do visível, depois de fazer uma série de considerações a propósito do destino histórico da pintura, escreve Merleau-Ponty (1964, p. 65):

(...) Da profundidade assim compreendida, não se pode mais dizer que seja 'terceira dimensão'. Em primeiro lugar, se fosse uma dimensão, seria antes a primeira: só há formas, planos definidos, se se estipula a que distância de mim se encontram suas diferentes partes. Mas uma dimensão primeira e que contém as outras não é uma dimensão, pelo menos no sentido comum de uma certa proporção pela qual se mede. A profundidade, assim compreendida, é mais bem a experiência da reversibilidade das dimensões, de uma 'localidade' global em que tudo está ao mesmo tempo, e da qual altura, largura e distância estão abstraídas, de uma voluminosidade que se exprime numa palavra ao se dizer que uma coisa está aí. 
Ao ler essa passagem, já percebemos que a integração da profundidade, nessa interpretação, procede de uma mudança de perspectiva por relação à semiótica clássica. Tratase de instaurar o centro da dêixis, habitado pelo sujeito da enunciação (Enunciador/Enunciatário), logo de saída, no plano mais abstrato do percurso gerativo. Esse gesto equivale, afinal de contas, apenas a assumir algo já defendido por Saussure, a idéia de que "o ponto de vista cria secundariamente a coisa", postulação que Hjelmslev (1966, p. 27) faz sua, nos seguintes termos:

No campo científico, pode-se muito bem falar em resultados definitivos, mas dificilmente em pontos de vista definitivos. A lingüística clássica do século XIX obteve resultados definitivos acerca do parentesco genético das línguas. Constituem um dos aspectos essenciais da lingüística. Mas nós os expomos aqui adaptando-os aos novos pontos de vista e posicionando-os numa perspectiva um pouco diferente daquela em que foram descobertos; por isso, nossa apresentação dessas matérias irá afastar-se, em seus princípios, da que se encontra nos manuais correntes sobre o mesmo assunto.

O interesse da visão de Hjelmslev, neste particular, está no abandono de qualquer veleidade de conhecimento positivista, na medida em que a "coisa" (objeto do conhecimento) dependerá, para ser estudada, de um ponto de vista, o que equivale a dizer: de um sujeito implicado no ato de conhecê-la, e isso não tem nada de inocente. Só uma leitura desatenta, anedótica, poderia supor que a lingüística pós-saussuriana tivesse abandonado por completo, em nome de alguma "objetividade" científica, o sujeito e o devir; seria esquecer o postulado primeiro desse paradigma, a saber, que as relações prevalecem sobre os termos que elas confrontam, isto é - como ficaria explicitado na investigação dos dinamarqueses -, que a complexidade é a regra e não a exceção.

Desde seu surgimento, na década de 1960, a semiótica da "Escola de Paris" vem elaborando modelos que oscilam entre as inspirações lógicas e topológicas, ou topológicodinâmicas. Para uma teoria de tipo gerativo, como é o caso - o sentido sendo pensado como trajetória entre níveis superpostos de organização, marcando-se os mais profundos como domínio do mais abstrato e constante, e os mais superficiais como domínio do mais concreto e variável -, a questão diz respeito, mais que tudo, aos estratos mais elementares do modelo, ali onde se pode estabelecer o confronto entre diferentes concepções da linguagem presentes nesta ou naquela escola ou tendência. A semiótica introduziu, na qualidade de "modelo constitucional", o quadrado semiótico, simulacro das articulações mínimas na instância fundamental de seu "percurso gerativo", e serviu-se amplamente dele como macchinetta descritiva, a ponto de ser muitas vezes lembrada, entre não-especialistas, apenas por esse dispositivo. Embora seu fundador, Algirdas Julien Greimas, tenha em diferentes ocasiões apresentado o quadrado como a "articulação lógica" de uma estrutura semântica elementar, trabalhos posteriores de colaboradores seus, como Jean Petitot e Per Aage Brandt, trouxeram numerosas razões para se ver o quadrado não como dispositivo lógico (no sentido aristotélico, clássico), mas antes topológico, em razão dos conceitos de relações que o embasam. Tendo discutido esses problemas com mais pormenor em outros estudos, limitamo-nos, no presente trabalho, a reter a pertinência da orientação topologizante, que extrai da solidão a semiótica, reinserindo-a no conjunto das ciências sociais de raciocínio comparável, como a antropologia lévi-straussiana ou a psicanálise freudiana. Já ninguém se espanta, hoje, com a idéia de uma topologização da significação, mas vale a pena recordar que isso parecia, num passado não tão remoto, especulação pura ou mera insensatez, não merecedora de maiores atenções. Paralelamente ao desenvolvimento das pesquisas topologizantes, que impeliam a semiótica na direção das ditas ciências "duras", foi-se fazendo todo um trabalho mais próximo à poética e à 
retórica, e que sempre se notabilizou pela orientação "temporalizante" de seu enfoque. Referimo-nos, antes de mais nada, à investigação de Claude Zilberberg sobre a tensividade, desde os anos 1970, e ao campo mais largo da "perspectiva tensiva", progressivamente enriquecida com a contribuição de outros semioticistas de relevo, tais como Jacques Fontanille. Uma e outra inflexão representam ampliação das ambições da semiótica greimasiana, mas em direções distintas.

\subsection{Contribuição da perspectiva morfodinâmica}

Houve uma época em que se nutriu a esperança de elevar a semiótica, do estágio "descritivo-conceptual" em que se achava, a um grau de rigor bastante superior, entrevendose a possibilidade de inseri-la enfim entre as teorias matematizadas de fato; ninguém ignora a sedução secularmente exercida, sobre os pesquisadores em ciências humanas, pela idéia de alçá-las à exatidão das chamadas ciências "duras". A intervenção da teoria das catástrofes (abreviando: TC; hoje é comum fazer-se também alusão ao campo sob a denominação de "morfodinâmica") na semiótica, bastante estrepitosa quando de seu surgimento, constituiu um desses momentos de fé prospectiva. Com base em avanços técnicos dos anos 1950 e 60, o matemático e filósofo René Thom intuiu e elaborou, em fins da década de sessenta, início dos anos 1970, certos postulados teóricos e epistemológicos que tinham a ambição, nada mais, nada menos, de conduzir a topologia ao estatuto de ciência fenomenológica, apta a modelizar um vastíssimo conjunto de acontecimentos atinentes a regiões do saber tão díspares quanto as transições de fases na física, o desenvolvimento embrionário na biologia, o comportamento de agressividade nos mamíferos superiores (etologia) ou ainda a regulagem arquetípica do imaginário, em antropologia. Durante cerca de duas décadas, foi grande o entusiasmo gerado em torno dessa teoria, tendo aparecido até mesmo diferentes correntes que reivindicavam filiação a seu domínio. No mundo anglo-saxão, assistiu-se ao surgimento de toda uma corrente fortemente dedicada à aplicação aos campos de saber mais diversos, impulsionada pelos trabalhos de um eminente matemático britânico, E. Christopher Zeeman. Tais aplicações iriam logo tornar-se objeto de severas críticas por parte de outros importantes especialistas das ciências exatas, em razão de certas deficiências técnicas, é bem verdade, porém mais amplamente em função de sua aspiração à modelização, nos mesmos termos, de mais ou menos tudo quanto lhes caía sob o olhar: comportamentos animais, tectonismo das placas, rebeliões nas prisões, flutuações da Bolsa de Valores.

Não se pode negar que a TC tenha suscitado, durante cerca de dez ou quinze anos (décadas de 1970 e 80), algum arrebatamento excessivo, para o qual contribuíam, aliás, seu nome bombástico, o carisma pessoal de R. Thom, o "ar do tempo" de um período que apreciava as grandes sínteses teóricas. Embora não se furtasse à larga divulgação de sua teoria, nos meios científicos e também fora deles (jornais, televisão ...), René Thom procurava explorar mais os aspectos epistemológicos e teóricos daquele conjunto, olhando com alguma suspeição para toda aquela agitação aplicativa dos anglófonos. Em mais de uma ocasião, deixou claras as distâncias que tomava por relação àquelas rápidas aplicações práticas da $\mathrm{TC}$, manifestando ao mesmo tempo os votos pela utilização e teste do seu sistema teórico e metodológico nas regiões cobertas pelas ciências humanas e pela filosofia. Entre as respostas relevantes a tais desejos, contam-se os trabalhos de Jean Petitot, que, já em 1977, publicava um importante artigo ("Topologie du carré sémiotique") em que propunha a esquematização do quadrado semiótico de Greimas com auxílio das chamadas "catástrofes elementares", num trabalho simultaneamente dotado de grande rigor técnico e carregado de conseqüências epistemológicas. 
Nesse como noutros ensaios, Petitot defende a idéia de que o inventário epistemológico básico da semiótica, ou seja, os conceitos indefinidos e indefiníveis que alicerçam o conjunto da construção teórica, deve ser reinserido no conjunto mais vasto das intuições fundadoras do estruturalismo lingüístico, do qual procede. São conceitos como relação, diferença, conjunção e disjunção, oposição, pressuposição, que remetem a primitivos tais como junção e posição, os quais, de acordo com sua argumentação, não seriam de cunho "lógico", ao contrário do que por um bom tempo se acreditou, e sim de cunho "topológico". De um certo prisma, isso corresponde à radicalização das metáforas espacializantes que, muitos já o haviam notado, caracterizam o conjunto das disciplinas ditas "estruturais" nas humanidades. Prosseguindo em seu raciocínio - e após ter demonstrado a inconsistência do quadrado de Greimas, quando interpretado em termos lógicos (boolianos) -, sustenta Petitot que é necessário reformular a teoria semiótica tendo-se em mente essas características fundamentais, e para tanto avança algumas sugestões originais. Mencionaremos aqui somente duas delas. A primeira prende-se à maneira de se trabalhar com a noção de "forma" em semiótica. A segunda concerne à "natureza" dos semas do nível fundamental do percurso gerativo e a sua conversão, quando da transição para o nível narrativo de análise; essa reformulação, se não constitui necessariamente um aprofundamento do modelo, corresponde com toda certeza a um espessamento dos conteúdos em apreço.

\subsubsection{A noção de "forma" em semiótica}

Petitot (1992b, p. 13-4) defende, em diferentes escritos, a tese de que a orientação hjelmsleviana, preconizando uma teoria da linguagem que se busque a si própria cada vez mais como uma "álgebra de formas", só pode ser desenvolvida coerentemente se tomarmos, nessa expressão, o termo formas como núcleo isotopante, e não o contrário. $\mathrm{Na}$ morfodinâmica, a concepção da "forma" está bastante próxima da sua definição fenomenológica, e comporta três momentos constitutivos:

(i) Uma extensão. É o espaço substrato $\mathrm{W}$ da forma F. No caso de uma forma visual, W está imerso no espaço; no caso de uma forma auditiva, W está imerso no tempo. Quando F for uma forma individualizável ( = não difusa), a extensão W será dotada de uma borda.

(ii) Um preenchimento da extensão $\mathrm{W}$ por qualidades sensiveis. São exemplos: cores, texturas, brilho, etc. (grandezas intensivas).

(iii) Para que haja forma, é necessário que o preenchimento da extensão $\mathrm{W}$ pelas qualidades sensíveis manifeste uma saliência, a qual permitirá à forma $\mathrm{F}$ destacar-se como fenômeno. A saliência fenomênica requer descontinuidades qualitativas. Tais descontinuidades formam um subconjunto $\mathrm{K}$ de $\mathrm{W}$, composto, no mínimo, pela borda, e também, freqüentemente, por linhas de descontinuidade internas a $\mathrm{W}$.

Essa descrição fenomenológica se situa na dependência direta das escalas de observação. Por exemplo, o julgamento de homogeneidade/heterogeneidade só pode fazer sentido nesta ou naquela escala: aquilo que é textura numa escala $X$ será visto como conjunto de $n$ subformas, noutra escala $\mathrm{Y}$, mais aproximada. Ora, tomando-se como centro de referência dêitica o sujeito descritor, é a profundidade do seu campo de presença - campo dos observáveis, nesse caso - que torna possível toda decisão sobre as escalas das formas a serem analisadas. Observa-se, no mais, a intervenção de parâmetros ligados tanto àquilo que mais tarde será formulado sob a rubrica "extensidade", quanto àquilo que reaparecerá sob a rubrica "intensidade", nas derivações recentes da teoria da linguagem com que estamos lidando.

$\mathrm{Na}$ tradição herdada pela semiótica, há três momentos fortes da abordagem do conceito de "forma", segundo anota Zilberberg (1995): 
1. A primeira é, em Saussure, a definição da forma pela diferença. Tal abordagem será adotada posteriormente por Jakobson, sobre o pano de fundo do binarismo, e irá desempenhar um papel de grande relevo nas ciências da linguagem do século XX, ao ganhar a adesão de outros grandes nomes das humanidades, como Lévi-Strauss e Lacan, entre outros. Ressalve-se todavia, ainda com Zilberberg (1996c, p. 10), que Saussure temperava desde logo essa postulação da forma como diferença: "Na língua, tudo se reduz a diferenças, mas tudo se reduz também a agrupamentos" (SAUSSURE, 1995, p. 177). A tradição estruturalista havia de fazer posteriormente prevalecer a diferença, através do privilégio concedido às relações disjuntivas;

2. Hjelmslev irá, por sua vez, vincular a forma ao limite e à dependência; por conseguinte, ao limite de vigência de uma dependência. Tal visão assemelha-se à abordagem de Thom (1991, p. 22), que por sua vez se inspira em Aristóteles. "Para Aristóteles, um ser, em geral, é o que está aí, separado. Possui uma borda, e está separado do espaço ambiente. Em suma, a borda da coisa é sua forma. Também o conceito tem uma borda: é a definição desse conceito".

É possível pensar, com Zilberberg, esse "limite de vigência" (comparável ao limite do domínio de um regime qualitativo, em TC), pela sua face temporal; paralelamente à clássica questão do "onde começa/termina" este ou aquele regime, estaremos interessados, então, em saber "quando começa ou termina" uma dependência constatada em dado contexto.

3. enfim, Brøndal ligará a forma à complexidade: o valor será, para ele, estabelecido na confrontação de um programa com seu anti-programa. Voltaremos, dentro em breve, a esse ponto.

São, portanto, aparentadas as idéias de "forma" em morfodinâmica e na tradição semiolingüística que leva de Saussure à Escola semiótica de Paris, passando por uma escala decisiva em Copenhague, com o incontornável trabalho epistemológico de Hjelmslev e Brøndal. Não há nada de casual nisso, se soubermos encará-las como etapas que se somam, para um olhar retrospectivo, na edificação de uma teoria da linguagem assentada sobre bases (trans-)posicionais, contanto que se compreenda "posição" como situação tanto espacial, quanto temporal.

1.1.2 Transição do nível profundo ao nível narrativo do percurso gerativo: a "conversão metapsicológica", segundo Jean Petitot

Ao se debruçar sobre um dos problemas que sempre (e hoje inclusivamente) constituíram dificuldade no modelo greimasiano, o da conversão entre níveis do percurso gerativo, Petitot (1992a) reconhece três aspectos implicados na passagem do nível profundo (fundamental) ao nível semionarrativo de análise:

(i) a conversão "formal". Trata-se, pensando na forma do conteúdo (Hjelmslev), da passagem de uma leitura paradigmática a uma leitura sintagmática e actancial dos esquemas catastrofistas.

(ii) a conversão por dualidade. Conversão dos semas profundos em relações actanciais entre sujeitos e objetos, entre sujeitos e outros sujeitos. Aquilo que era um sema posicionado dentro de uma estrutura elementar passa a ser visto como uma relação juntiva $(\mathrm{S} \cap \mathrm{O}$, por exemplo).

(iii) a conversão metapsicológica. Os problemas aí levantados dizem respeito, já na substância do conteúdo (Hjelmslev), à intencionalidade dos sujeitos narratológicos e ao valor dos objetos de valor; é a conversão metapsicológica que melhor deveria fazer-nos apreender a semiótica como uma antropologia do imaginário. 
Embora a questão não seja posta nesses termos por Petitot, a introdução desse terceiro tipo de conversão é uma maneira de responder às indagações suscitadas pela equivocidade, desde sempre mantida na semiótica, entre duas acepções do valor: (i) os semas do nível profundo são valores, num sentido próximo da acepção saussuriana de "valor diferencial"; (ii) os valores buscados pelos sujeitos da narratividade, sobre serem também valores diferenciais, ganham o estatuto de valores axiológicos, bases para as confrontações ideológicas encenadas nos textos.

Uma hipótese forte defendida pelo semioticista, nesse particular, é a de que os semas encontradiços na superfície e nas profundezas do modelo seriam de naturezas distintas; como pensar as relações entre os semas nucleares (exteroceptivos) das figuras lexemáticas de superfície, por um lado, e os classemas categorizantes, selecionantes (interoceptivos) do nível fundamental do percurso gerativo? A essa pergunta, Petitot responde pela postulação de que os classemas do nível profundo, e apenas eles, possam ser interpretados como "pregnâncias assemânticas". Isso demanda alguma explicação, que nos obriga a um desvio por territórios aparentemente sem conexão com esses em pauta, mas só aparentemente. Uma parte importante das reflexões de Thom recai sobre as regulações biológicas e sobre tudo aquilo que permite discernir o psiquismo humano do psiquismo animal. Resumindo brutalmente: nos animais superiores, Thom admite a existência de uma dialética muito peculiar entre o que denomina "formas salientes" e "formas pregnantes". As formas (Gestalten) percebidas pelos mamíferos superiores em seu ambiente - descontinuidades perceptivas contra o pano de fundo sobre o qual se destacam - constituem o que ele chama "saliências"; nesse mundo fenomênico, entretanto, há formas privilegiadas, aquelas que são dotadas de um conteúdo "existencial" básico para a sobrevivência da espécie. No mundo animal, não há senão três dessas formas ditas "pregnantes": o predador, a presa e o parceiro sexual. Assim que uma delas entra no campo perceptivo do animal (o "sujeito" dessa história), ocorrem modificações consideráveis em seu "estado de ânimo", e ele adotará de imediato comportamentos previsíveis, em direção a elas (caso da presa e do parceiro sexual) ou para longe delas (caso do predador). O campo fenomênico das formas salientes acha-se investido, portanto, por essas forças que são, em última análise, as pregnâncias, e que, ao seu modo, emprestam "sentido" a tal campo perceptível; a sintaxe narrativa passa a ser vista globalmente, então, como um processo de difusão de pregnâncias. Apoiado nessas considerações é que Petitot vai propor que se tome a diferença entre os semas interoceptivos (profundos) e os semas exteroceptivos (superficiais) como uma diferença análoga à diferença entre formas biologicamente pregnantes e formas perceptivamente salientes, assumindo a tese de que se pode assim compreender melhor o alcance antropológico e psíquico das raízes do imaginário estudadas pela semiótica narrativa. Na qualidade de traços do "sentido da vida", os semas profundos seriam como que "buracos negros" da representação, e sua extrema recorrência nos mais diversos discursos daria testemunho do fato de não sabermos nunca ao certo o que é que significam. Daí a denominação de "pregnâncias assemânticas" para oposições do nível fundamental, tais como "vida VS morte" e "natureza VS cultura": sua significação, inacessível por via direta, tem de ser encenada de modo mediato pelos percursos sintáxicos da circulação dos objetos entre sujeitos (sintaxe narrativa).

Conclusão tirada por Petitot (1992a, p. 375): o sentido que é o objeto da semiótica greimasiana não pode ser assimilado à "significação", pois, ao contrário desta, ele "diz respeito a um imaginário de natureza metapsicológica, um imaginário do corpo cujo conteúdo é regulatório e pulsional, afetivo, em suma: tímico. É um imaginário organizado por pregnâncias." O "sentido da vida" figura, nesse raciocínio, como busca de valores problemática antropológica, sob certo ponto de vista, e igualmente metapsicológica, embora 
não de todo numa acepção freudiana. A equivalência entre "o indizível dos valores existenciais" (axiologia) e "o indizível dos valores estruturais" (diferença para Saussure, dependência para Hjelmslev), eis a especificidade da perspectiva greimasiana, que lhe constituiria, a seu ver, a dificuldade e o preço. O investimento tímico seria o ponto em que os valores estruturais do nível profundo viriam a converter-se em pregnâncias subjetivas a serem posteriormente investidas nos objetos, e nesse processo estariam entrelaçados a substância e a forma do conteúdo, uma metapsicologia e uma gramática narrativa.

Uma amostra simples como essa que acabamos de reportar já indica, em todo caso, como a problematização da semiótica greimasiana, em Petitot, tende a nos conduzir para terrenos pouco freqüentados pelos especialistas da área, e ajuda-nos a entender, ao mesmo tempo, que suas propostas tenham provocado tantas reações de estranhamento ou tenham sido simplesmente ignoradas por muitos estudiosos que não lhes reconheciam pertinência. Há algo que lamentar nesse fato, não porque as pessoas devessem todas conceber a semiótica exatamente da mesma maneira, mas porque são discussões que problematizam por dentro a edificação da semiótica, e que, além do mais, lançam várias pistas para a interação da semiótica com as disciplinas vizinhas, nas ciências humanas em primeiro lugar, mas igualmente no quadro ampliado da episteme estrutural, que se estende para lá das humanidades.

Isso posto, não custa muito prever as críticas a que se presta a leitura morfodinâmica da semiótica. Tecnicamente falando, as esperanças longamente acalentadas de matematização da teoria esbarram em grandes dificuldades, ligadas ao grau de complexidade que se tem de admitir para estruturas situadas ainda no quadro das "catástrofes elementares" (cuja topologia continua a comportar zonas obscuras), sem falar nas catástrofes não-elementares, para as quais se prevê um drástico aumento do número de parâmetros a levar em conta. Para além das questões colocadas, de resto, pela pouca atenção concedida aos estratos mais superficiais da geração do sentido - o enriquecimento verificado, por exemplo, quando da transição entre estruturas semionarrativas e estruturas discursivas, comportando estas muito maior variedade de conteúdos do que as precedentes -, deve-se frisar o fato de a interpretação catastrofista propor um certo comprometimento de tipo "metapsicológico", acima mencionado, para a natureza dos semas da semântica profunda, os quais seriam tanto mais determinantes do comportamento do sujeito, quanto mais opaca sua significação. Essa interpretação, que engaja a teoria num quadro de crenças "realista", tem seu valor na discussão das premissas da reflexão sobre a linguagem, mas é difícil decidir se, ao adotá-la, reformulando as "profundezas" do modelo, e efetuando um mergulho nas profundas da substância em si, não cairíamos nas mesmas aporias que Greimas sempre tratou obstinadamente de evitar. $\mathrm{O}$ problema assim levantado seria, em outras palavras: até que ponto podemos "aprofundar" o alcance do modelo, "cavando" mais e mais para "baixo", antes de ver transformadas as profundezas em abismo, em queda sem fim? Deve haver algum ponto nas estruturas profundas que configure um horizonte ontológico "abaixo" do qual cessa a pertinência semiótica, e sem cujo reconhecimento não se vê bem como constituir uma disciplina autônoma. Quanto mais o modelo tende a explorar a vizinhança desse limite, mais se erguem as dificuldades próprias ao tratamento dos limiares e sua gradualidade.

\subsection{A profundidade "vertical" em Greimas}

Desde a elaboração do percurso gerativo de Greimas, cuja noção se entrevia "em germe" no livro Semântica estrutural (1966), porém só seria consolidada na década de 1970 para receber formulação bem explícita no primeiro tomo do Dicionário de semiótica ( cuja 
primeira edição francesa é de 1979), é possível detectar a intervenção de uma certa noção de "profundidade", na própria maneira de dispor as problemáticas umas "acima" das outras, numa espécie de edifício sempre em construção, cujo topo - terminus ad quem - comporta a grande variedade de elementos correspondentes ao chamado nível discursivo, e cujos alicerces - nível fundamental, dito terminus a quo - guardam as poucas oposições mais genéricas suscetíveis de subsumir o conjunto dos significados mais globais de um dado texto. Entre esses dois extremos, medeiam as estruturas semionarrativas, que contêm "mais" do que o nível fundamental e "menos" do que o nível discursivo. O nível fundamental é também chamado, segundo as preferências de uns ou outros, de nível "profundo". A "profundidade" presente nesse modelo clássico está vinculada, portanto, à abstração, à simplicidade e à constância dos conteúdos aí reconhecidos. Greimas \& Courtés ([1993?]) deixam bem estabelecida a concepção de profundidade no dicionário:

(i) Antes de mais nada, a semiótica opõe as estruturas profundas às estruturas de superfície, estas ligadas ao domínio do observável e aquelas consideradas como subjacentes ao enunciado. Duas possíveis confusões são aludidas e afastadas pelos próprios autores: a primeira refere-se às conotações ideológicas de "profundidade", que tenderiam a fazer assimilar ao profundo o autêntico; a segunda é a tentação de se confinar à profundidade aquilo que é de ordem semântica, reservando à superfície a sintaxe, concepção que Greimas \& Courtés descartam logo de saída, postulando a necessidade de se trabalhar com um componente sintáxico e outro semântico em todos os níveis do seu percurso gerativo;

(ii) em seguida, observam os semioticistas que "profundidade" e "superfície" só fazem sentido dentro de uma visão global da geração do sentido, segundo a qual as estruturas de maior complexidade são geradas a partir de estruturas mais simples. O número de níveis a serem admitidos no percurso gerativo, orientado por imperativos operatórios, está sempre sujeito a remanejamentos e o que deve ser mantido em mente é o princípio de "acréscimo do sentido" de um nível inferior a seu imediatamente superior, mediante complexificação das estruturas.

Já se apontava, nesse mesmo artigo, o cunho espacializante de um tal modelo: "profundo e superficie são duas metáforas espaciais, relativas ao eixo da verticalidade" (GREIMAS \& COURTÉS, [1983?], p. 352). Do mesmo modo, a definição de "profundo" é colocada como algo relativo, uns níveis sendo mais superficiais ou mais profundos sempre em relação a outros, numa descida às profundezas que só se interrompe mediante a decisão (metateórica, na verdade) de situar, na instância a quo (no ponto mais profundo), a estrutura elementar da significação, articulada em quadrado semiótico.

No rastro dessas asserções, Zilberberg (1988) expressa um ponto de vista semelhante, ainda que propondo um percurso gerativo modificado, em que as instâncias mais "profundas" são ocupadas por valores de um tipo que chama de "missivo", relacionados à continuação e à parada: "O nível mais profundo - profundidade, para nós, significa abstração, direção e limite da análise - é o nível tensivo $\left(\mathrm{N}_{1}\right)$; a alternância que lhe diz respeito se dá entre: remissão e emissão"

Independentemente das decisões específicas de Zilberberg acerca da natureza dos valores mais profundos, a inspiração geral do modelo continua a mesma, quanto à sua organização vertical e ao princípio do progressivo incremento de sentido, à medida que se "sobe" de patamar em patamar. Anos mais tarde, essa idéia de profundidade "na vertical" passaria a estar acompanhada, na semiótica, por uma profundidade, se se pode dizer, "na horizontal", da qual devemos agora dar alguma notícia, para verificar, no final das contas, se esta pode ser tida como proveitosa também no que se refere à capacidade descritiva, prática, do modelo. 


\section{A profundidade no eixo "sagital"}

Não é somente como extremidade de um eixo vertical que se concebe a profundidade, em semiótica. A partir do instante em que se atenta para as especificidades do espaço discursivo, abrem-se perspectivas diferentes, como bem pontua Coquet (1997, p. 10): "Conforme sabemos, o espaço discursivo não é euclidiano, dado que o processo (o ato) está centrado no corpo e seu movimento. Para retomar Merleau-Ponty, é 'um espaço contado a partir de mim'."

Vale a pena prosseguir um pouco na leitura dessa página de Merleau-Ponty (1964, p. 59): “[...] é um espaço contado a partir de mim, como ponto ou grau zero da espacialidade. Não o vejo por intermédio de seu invólucro exterior, vivo-o por dentro, estou englobado por ele. Afinal de contas, o mundo está em torno de mim, e não diante de mim". Reflexão sobre a espacialidade, é certo, em Merleau-Ponty, mas que se presta à generalização para o conjunto das instâncias enunciativas.

Esse "eu" posicionado no centro do campo discursivo procede de uma conceptualização que salienta as dependências entre enunciação e enunciado, bem como os aspectos sensíveis da produção e recepção do discurso. Isso se explicita numa sugestão de Fontanille (1998) acerca do "campo discursivo". Nesse escrito, o semioticista propõe algumas saídas para um problema levantado alguns anos antes, em Greimas \& Fontanille (1991), a saber: de que modo formular a mediação propriamente semiótica entre o domínio interoceptivo, ligado aos "estados de alma" do sujeito, e o domínio exteroceptivo-figurativo, ligado aos "estados de coisas" do mundo objetal? Já nessa época, Greimas \& Fontanille (1991) sustentam que a passagem entre esses domínios deve ser operada pelo corpo, em sua especial qualidade de partícipe de um e de outro.

No dizer de Fontanille (1998), o primeiro ato que deixa marcas no discurso sob a forma da dêixis enunciativa é uma tomada de posição de um corpo-que-percebe no interior de um mundo sensorial. Essa tomada de posição divide tal mundo perceptivo em dois subdomínios: (i) o domínio INTERNO, interoceptivo, que fornecerá o Plano do Conteúdo; (ii) o domínio EXTERNO, exteroceptivo, que fornecerá o Plano da Expressão.

Esse campo de presença instaurado inicialmente conta com dois tipos de "profundidades", tais como as reconhece Fontanille: (i) uma profundidade INTERNA, puramente sensível e intensiva (podemos intuí-la como uma profundidade associada ao tempo); (ii) uma profundidade EXTERNA, perceptiva e extensiva, que irá definir o lugar dos horizontes desse campo (nesse caso, o que se contempla é uma profundidade ligada ao espaço).

São propriedades topológicas mínimas do campo assim esboçado: um CENTRO de referência (nas visões mais consagradas, é a interseção dêitica eu-tu/agora/aqui); PROFUNDIDADES que determinam a posição e a forma das fronteiras ou horizontes desse mesmo campo, horizontes para além dos quais já não se reconhecem presenças perceptíveis.

É nos seguintes termos que Fontanille (1998, p. 97) define a profundidade prevista pelo modelo:

[...] falamos na profundidade do campo posicional do discurso, concebida como uma tensão entre um centro e os horizontes, tensão que depende das variações da intensidade e da extensão perceptivas. Para o centro sensível do discurso, portanto, só há profundidade se houver uma mudança de equilíbrio entre a intensidade e a extensão, e uma variação na 
tensão entre o centro e os horizontes. [...] Logo, a profundidade é, não uma posição, porém um movimento entre o centro e os horizontes.

Assinalemos, aliás, que a profundidade que une/separa o centro e os horizontes do campo é um intervalo. Ora, um intervalo deve ser percorrido a alguma velocidade, e essa velocidade responde pela deformabilidade desse percurso: percorrido de maneira rápida (disjuntiva) ou lenta (restauradora da gradualidade, das etapas intermediárias). Temos aqui um parâmetro simples, o andamento (ou velocidade), que define por si só diferentes "estilos" dos percursos narrativos. A profundidade proposta é medida pelas correlações entre intensidade e extensidade identificáveis nesse campo posicional. Em princípio, quanto mais distante do centro dêitico (maior extensidade), menor a intensidade sensível - sensível significando, no caso, "perceptiva" e "tímica" simultaneamente; quanto mais próximo do centro dêitico (menor extensidade), maior o impacto sensível, logo a intensidade. Nesse quadro, intensidades e extensidades estão variando em proporção inversa; se representarmos a dependência entre ambas em coordenadas cartesianas tais que o eixo $x$ corresponda à extensidade e o eixo $y$, à intensidade, obteremos:

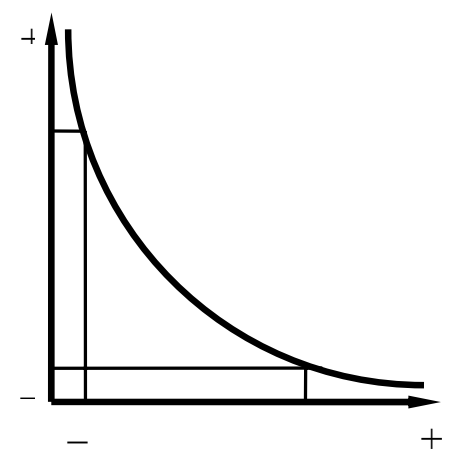

Prossegue Fontanille (1998, p. 219), situando enfim o que está em jogo num tal modelo, quando o inserimos no panorama das aquisições recentes em semiótica: "O campo de presença recebe, por isso, dois tipos de determinações: determinações TOPOLÓGICAS (centro, horizontes) e determinações TENSIVAS (intensidade, extensidade)". Distribuindo visualmente:

\begin{tabular}{|l|l|}
\hline \multicolumn{1}{|c|}{ Determinações topológicas } & \multicolumn{1}{|c|}{ Determinações tensivas } \\
\hline $\begin{array}{l}\text { plano SINTÁXICO: relações entre actantes } \\
\text { posicionais }\end{array}$ & $\begin{array}{l}\text { plano SEMÂNTICO: intensidade e } \\
\text { extensidade } \\
\text { fonte - alvo - obstáculo (actante de controle) }\end{array}$
\end{tabular}

A metade sintáxica desse quadro comporta, sobre a base formada pelo campo discursivo, um tipo especial de actantes, a que Fontanille (1998) chama "actantes posicionais", por oposição aos "actantes transformacionais" que povoam tradicionalmente a gramática semionarrativa (sujeito, objeto, destinador). Numa concepção vizinha da fenomenologia, Fontanille classifica três actantes posicionais implicados no ato perceptivo: a fonte (que apreende e sente), o seu alvo (que é apreendido) e um actante de controle, o qual comanda, regula o acesso da fonte ao seu alvo, podendo facilitar-lhe o acesso, agindo como 
elemento de ligação, ou dificultar-lhe a apreensão, à maneira de um obstáculo: exemplo, todos os tipos de "lentes" ou anteparos postos entre o sujeito perceptivo e seu "informante" ou objeto.

Além de ajudar a reorientar o modelo na direção do sensível e das múltiplas relações estabelecidas entre enunciado e enunciação - trabalhando no âmbito da arbitrariedade hjelmsleviana -, a noção de "campo de presença" tem também sua utilidade quando se trata da descrição prática de textos específicos, isto é, daquilo que Hjelmslev denomina adequação. Seja, para brevíssima ilustração, o seguinte texto de um poeta contemporâneo:

\section{ZERO GRAU}

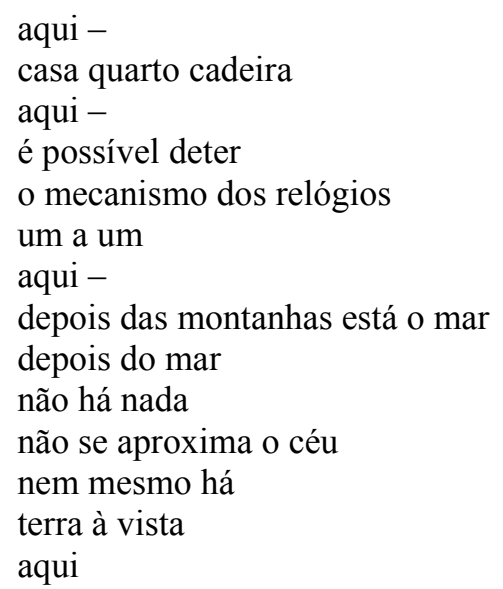

(POLITO, 2002, p. 288)

Primeira observação, do ponto de vista da extensidade do campo focalizado: o movimento inicial é um encolhimento da extensão, um estreitamento do campo: o aqui se estende primeiramente à casa, depois ao quarto apenas (contido na casa), enfim à cadeira (contida no quarto); esse estreitamento prepara o efeito posterior de contraste com as figuras da amplidão que dominam a segunda metade do poema. Notar a negação da periferia do campo, ou melhor, não se nega a periferia, mas nega-se a ocupação dessa periferia. Como se não permanecesse, nela, nada além da pura extensidade (dimensão), à espera de vir a ser habitada pelos actantes virtualizados, o "céu" e a "terra". Uma extensidade sem ocupação por actantes? Contraste entre o vazio da periferia do campo e o domínio da proximidade do centro dêitico [aqui], estando este ocupado por "casa", "quarto", "cadeira", etc. Vale assinalar a prioridade figural da intransitividade, cuja manifestante temporal é a "detenção do mecanismo dos relógios" - sem esquecer a imemorial ligação sinestésica entre o gélido (zero grau) e o estático ou imóvel - e cuja manifestante espacial corresponde àquele distanciamento exponencial retratado nos últimos versos. É aí que se nega duplamente a aproximação: "não se aproxima o céu", por um lado, e, por outro, não há "terra à vista", o que se pode ler como ausência da fórmula ritual "- Terra à vista!" (= contato iminente) atribuída aos antigos navegantes. Esse "não se aproxima o céu", nas proximidades do final do texto, é bem o contrário daquele verso que abre um dos poemas intitulados "Spleen", nas Flores do mal de Baudelaire: "Quand le ciel bas et lourd pèse comme un couvercle..." [Quando o céu baixo e grave pesa como tampa] - dois "céus" diferenciados diametralmente segundo a categoria da aderência (contato VS não-contato), cf. o Hjelmslev da Categoria dos casos. No soneto de Baudelaire, um céu que ganha os atributos da "gravidade" e da "compacidade", aproximandose a tal ponto que entra em contato com a terra habitada, oprimindo-a. Ao contrário, o poema 
de Ronald Polito afasta ao máximo o céu, situando-o além do "nada" que está além do mar, que por sua vez fica além das montanhas. Um céu tanto mais abstrato quanto mais distante do observador. Impossível deixar de pensar num curto poema de Fernando Pessoa, patrimônio comum dos falantes do português, em que essa homologia vem registrada de maneira explícita:

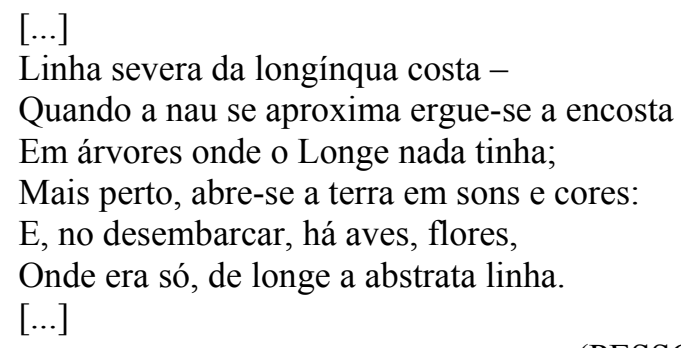

(PESSOA, 2001, p. 78)

É a mesma "linha", embora não seja bem a mesma linha, que abre e fecha essa segunda estrofe do poema, ensanduichada entre a primeira e a última; na primeira ocorrência, surge com a marca tímica de severa, mas, na última ocorrência, vem qualificada como abstrata, atributo cognitivo. Eis ilustrada, canonicamente, a correlação entre, por um lado, maior ou menor profundidade (distância do centro dêitico, na ocorrência um sujeito observador) e, por outro, maior ou menor grau de abstração: o que aparecia a distância como elemento geométrico uno (logo, construção do intelecto: a "abstrata linha", que fala em essência ao entendimento e que é captada, do ponto de vista sensorial, unicamente pela visão) revela-se, na proximidade, como uma multiplicidade de elementos figurativos, aves, flores, sons e cores, ou seja, não é mais exclusivamente a visão que instrui o observador, mas intervém também agora o possível conhecimento por meio de outros sentidos, como a audição. Paralelamente à atribuição do uno à região da profundidade e do múltiplo à região da proximidade, observa-se a coloração afetiva com que se tinge o Longe: os epítetos "severa" e "abstrata" aplicados igualmente à "linha" entram forçosamente em ressonância e não se pode deixar de notar-lhes algo de disfórico nesse contexto, pois o abstrato pode vir conotado como "abstruso", "obscuro", assim como o severo se presta não apenas à interpretação (átona) de "exato", mas ao mesmo tempo à interpretação (tônica) de "áspero, duro".

\section{Conclusões provisórias}

Passada, há tempos, a época em que se podia trabalhar com os textos de maneira relativamente livre, valendo-se o analista mais dos meios advindos da sua própria intuição e formação pessoal, vivemos um momento em que é preciso construir modelos e seus instrumentos descritivos. Ninguém imaginaria que estes substituam algum dia os recursos próprios do crítico, do scriptor, mas é necessário contribuir com a tarefa coletiva da edificação de uma disciplina, no caso a semiótica do discurso. Greimas conservou ao longo da vida a preocupação de elaborar um corpo de conhecimentos não apenas rigoroso, como também suscetível de ser utilizado com proveito e testado por outros pesquisadores, em condições as mais díspares. O preço a pagar, pois que também não se tem nada de graça ..., é a humildade de se tentar apreender uma teoria e uma metodologia de grande riqueza interna, que exige a assimilação de toda uma metalinguagem própria, tida por alguns como rebarbativa. A nossos olhos, é compensador pagar para ver. Quanto aos resultados obtidos até 
o momento na questão que aqui nos ocupou, todavia, nunca será demasiada a prudência. Parece-nos, sim, ter havido algum ganho de inteligibilidade desde que a "profundidade" vem agitando as mentes nas plagas semióticas. Demarcar o lugar que cabe a cada problemática, no seio de um modelo integrador, já é alguma coisa. Conclusões sobre o quanto possa haver de generalizável em tais resultados, porém, pedirão um bom número de estudos aplicados, para o teste dos modelos propostos, e em especial de estudos comparativos entre objetos provenientes de culturas diversas. Isso exige um certo tempo.

\section{Referências Bibliográficas}

COQUET, Jean-Claude. La quête du sens. Paris: PUF, 1997.

FONTANILLE, Jacques (ed). Le devenir. Limoges: PULIM, 1995.

Sémiotique du discours. Limoges: PULIM, 1998.

GREIMAS, A. J. Sémantique structurale. Paris: Larousse, 1966.

GREIMAS, A. J. \& COURTÉS, J. Dicionário de semiótica. Trad. Alceu Dias Lima et al. São Paulo: Cultrix, [1983?].

GREIMAS, A. J. \& FONTANILLE, J. Sémiotique des passions. Paris: Seuil, 1991.

HJELMSLEV, Louis. Le langage. Paris: Minuit, 1966.

MERLEAU-PONTY, Maurice. L'œil et l'esprit. Paris: Gallimard, 1964. (Coll. Folio-Essais)

PESSOA, Fernando. Horizonte In: Obra poética. Rio de Janeiro: Nova Aguilar, 2001

PETITOT, Jean. Topologie du carré sémiotique. Études littéraires, X, 3. Québec: Univ. Laval, 1977.

POLITO, Ronald. Zero grau. In: DANIEL \& BARBOSA (Orgs). Na virada do século: poesia de invenção no Brasil. São Paulo: Landy, 2002, p. 288.

. Théorie des catastrophes et structures sémio-narratives. Actes Sémiotiques - Documents GRSL, V, 47-48, 1983.

. Morphogenèse du sens I. Paris: PUF, 1985.

. Physique du sens. Paris: Ed. du CNRS, 1992a.

. L'esthétique transcendantale ou le De structura pingendi d'Albert Aymé. In: AA. VV.

Albert Aymé, rétrospective 1960-1992. Paris: E. N. S. Beaux-Arts, 1992b.

SAUSSURE, Ferdinand de. Cours de linguistique générale. Paris: Payot, 1995.

THOM, René. Prédire n'est pas expliquer. Paris: Eshel, 1991.

TOURNIER, Michel. Le miroir des idées. 2. ed. Paris: Mercure de France, 1996.

ZILBERBERG, Claude. Raison et poétique du sens. Paris: PUF, 1988.

. Plaidoyer pour le tempo. In: FONTANILLE, Jacques (ed). Le devenir. Limoges:

PULIM, 1995. 